\title{
Multiple choice questions and essay questions in assessment of success rate in medical physiology
}

\author{
Ghassan Th. Saeed* \\ Affan E. Hassan* \\ Hanan L. Al Omary* \\ Zainab M. Alawad*
}

\author{
MBChB, PhD \\ MBChB, PhD \\ MBChB, PhD \\ MBChB, MSc
}

\section{Abstract:}

Fac Med Baghdad 2017; Vol.59, No.4 Received: June.2017 Accepted: Dec .2017

Background: Assessment is an important part of the learning cascade in education. Students realize it as an influential motivator to direct and guide their learning. The method of assessment determines the way the students reach high levels of learning. It has been documented that one of factor affecting students' choice of learning approach is the way how assessment is being performed. Many methods of assessment namely multiple choice questions, essay questions and others are mainly used to assess basic science in knowledge undergraduate education. Objectives: The aim of this study is to compare multiple choice questions (MCQ) and essay questions (EQ) (record the success and failure rate of multiple choice questions (MCQ) and essay questions (EQ)) in regards to the Physiology questions.

Methods: A retrospective study was done in which the results of the physiology exams -held in the medical college in Baghdad University -in 2010 are recorded. The number of students underwent the exam was 255. A total of 100 essay questions (EQs) and 100 multiple choice questions (MCQs) were evaluated from the written examinations delivered to second year medical students questions belonged to final examination.

Results: Regarding essay questions that have been answered, 33.5\% of the questions were not answered as a total. 188 students out of 255 had succeeded which represent $73.7 \%$ of the students. Out of 78 marks for MCQ, 46.33 had been achieved, and out of 22 marks for essay 12.9 have been achieved. the success in MCQ questions was $82.9 \%$ while in the Essay questions was $67.7 \%$ and the failure in both types was $12.5 \%$. Out of 100 questions for both MCQ and Essay questions 55.1 $1 \pm 7.9$ questions were answered for the MCQ and 51.1 \pm 15.3 Essay questions were answered. In general the percentage of the succeeded students was $73.7 \%$ and that of failed students was $26.3 \%$.

Conclusion: There is no significant difference in the success rate between MCQs and EQs.

Keywords: assessment, multiple choice questions, essay questions.

\section{Introduction:}

Assessment has been known as the 'one biggest effect on how students approach their learning' (1). The estimation of the competence of undergraduate medical students is a very critical job, because in the future, these students are supposed to be physicians and have to be facing human lives (2). Assessment can lead students to focus on certain topics (i.e. it can define what students study); it can also change students' learning approaches (and so define how the studying is completed) (3). Feedback on assessment process has an important part to play in underpinning student learning. Immediate feedback is provided on wrong and incomplete responses, and students are able to use this feedback in repeating the attempt to answer the question. Students have been observed attempting the questions and were seen to answer them in different ways, with most students using short phrases but some using full and carefully constructed sentences and some using note form (4). Sadler contend that in order for feedback to be

* Dept. of Physiology / College of Medicine / University of Baghdad.hanaa-qdmi@yahoo.com effective, $a$ move must be done to close the gap between the student's level of understanding at that time and the level expected by the teacher (5). There are different methods to assess the knowledge domain which include free response examinations (Long Essay Questions, Short answer Questions, Modified Essay questions), Multiple choice questions, Key feature questions, Self-assessment and peer- assessment. Every one of these ways has its pros and cons and is attended to assess different levels of bloom's taxonomy. No single method of evaluation is better than the other and maybe a reliable and valid evaluation needs a combination of these methods (6). It is very understandable that conduction of a precise assessment is not only dependent on the cognitive aspect of question, but there are many factors which play a role such as, reliability, content and building of questions validity, financial and human resources (7). The objective of this study is to demonstrate and to compare multiple choice questions (MCQ) and essay questions (EQ) in their failure and success rate. 


\section{Materials and Methods:}

The study is a retrospective study in which the results of the physiology exams -held in the medical college in Baghdad University -in 2010 are recorded. The number of students underwent the exam was 255. All the questions which were in the exam were constructed by the faculty members then these were put forward to a question review committee and after its approval the questions were introduced into the question bank. A total of 100 EQs and 100 MCQs were corrected from the written examinations delivered to second year medical students questions belonged to final examination.

Statistical analysis: SPSS15' program was used to tabulate and analyze the data. The Mean \pm standered deviation was calculated and the percentage of the answered questions was measured also. Student's $t$ test was used to examine the differences. A $p$ value less than 0.05 was considered significant.

\section{Results:}

Concerning the essay questions that were not answered, it was found that $19.8 \%$ of students did not answer one question and $13.7 \%$ did not answer more than one question. $33.5 \%$ of the questions were not answered as a total. Table 1 shows 188 students out of 255 had succeeded which represent $73.7 \%$ of the students.

Table 2 shows the Comparison between marks of the MCQ and Essay questions, and it shows highly significant difference between them. It is obvious that out of 78 marks for MCQ, 46.33 had been achieved, and out of 22 marks for essay questions 12.9 have been achieved.

Table (1): Frequency of successes and failure among student

\begin{tabular}{lll}
\hline & Number & $\%$ \\
\hline Student successes & 188 & $73.7 \%$ \\
\hline Student failed & 67 & $26.3 \%$ \\
\hline Total & 255 & $100 \%$ \\
\hline
\end{tabular}

Table (2): Comparison between marks of the MCQ and Essay questions

\begin{tabular}{lllll}
\hline & $\begin{array}{l}\text { MCQ } \\
\mathrm{N}=78\end{array}$ & mark & $\begin{array}{l}\text { Essay mark } \\
\mathrm{N}=22\end{array}$ & P value \\
\hline Mean \pm SD & $46.33 \pm 9.203$ & $12.99 \pm 4.717$ & 0.0001 \\
\hline
\end{tabular}

Taking into consideration the failure and success in each type of questions it was observed that the success in MCQ questions was $82.9 \%$ while in the EQs was $67.7 \%$ and the failure in both types was $12.5 \%$ (table 3 ).

Table (3): Success and Failure according to type of questions

\begin{tabular}{lll}
\hline & Number & $\%$ \\
\hline Success MCQ & 213 & $82.9 \%$ \\
\hline Success Essay & 174 & $67.7 \%$ \\
\hline Failed both & 32 & $12.5 \%$ \\
\hline
\end{tabular}

Out of 100 questions for both MCQ and EQs 55.1 \pm 7.9 questions were answered for the MCQ and 51.1 \pm 15.3 EQs were answered. Those were compared to each other and no significant difference was found between them (Table 4).

Table (4): Distribution of the number of questions answered.

\begin{tabular}{|c|c|c|c|}
\hline & MCQs & Essay questions & $\mathrm{P}$ \\
\hline $\begin{array}{l}\text { Number of } \\
\text { questions } \\
\text { answered }\end{array}$ & $55.1 \pm 7.9$ & $51.1 \pm 15.3$ & 0.05 \\
\hline
\end{tabular}

\section{Discussion:}

It was observed that the percentage of students who did not answer more than one essay question was significantly less than those who did not answer one question which means that a good number of the students had answered the EQs. Some studies showed that it was difficult to achieve the mean score of 50\% (pass mark) in EQs which suggests that the students are weak in essay writing (7).

Out of 255 only 67 students failed and the percentage of success was $73.7 \%$. The average total marks for MCQ was $46.3 \pm 9.2$ out of 78 marks for this type of questions, while for the Essay, it was $12.9 \pm 4.7$ out of 22 marks. Which means that nearly half of the questions of both types were answered correctly, and obviously the percentage of success in the MCQ questions was high (82.9\%) and the success rate for the Essay questions was high too $(67.7 \%)$.This agrees with a study done by T.M. Nandan and his teamwork who found that achievement in MCQ based assessment was significantly better than that in essay kind of assessment ( 8 ). Other studies had found that there is no significant difference in success rate between EQ and MCQ as each one has certain properties (9).Other studies found that $51.34 \%$ had achieved success in the EQ and $64.71 \%$ in the MCQs (10) .Well constructed MCQs have a greater ability to test knowledge and factual recall but they are less powerful in assessing the problem solving skills of the students. A large proportion of curriculum can be tested in a single sitting. The scoring is very easy and reliable using computer software, but the construction of good MCQs is difficult and needs expertise. Generally MCQs stimulate students to make a superficial and exam oriented study $(11,12)$. On the other hand the Essay questions need training to avoid inter-rater variability (13). Khan and Aljarallha had found also that there is no significant difference between Essay and Multiple choice questions in relation to the type of questions (recall ,comprehension or problem solving ), but they observed that Multiple choice question is a better test of cognitive skills than the essay question although when the proportions of the two forms of questions addressing the different levels of cognitive domain were compared, there was no significant statistical difference among the level of cognition 
tested . It is also inferred that constructing an Essay questions might be technically more difficult than an MCQ

The finding of this study is similar to that reported by Pepple et.al (14) (average score of EQ was $47 \%$ and 64\% for MCQ). On the other hand other studies showed that the higher students' achievement in MCQs than in essays could be related to the disadvantages of the essays that involve subjective judgment of the examiner (having lower reliability than the MCQs) (15). MCQs can test the cognitive knowledge of students and they can assess a wide range of information and understanding of subjects (16), however, poor performance of students in essay questions may mean inability of presenting their knowledge in a logical sequence and an understandable way (17). Good MCQ design with obvious, clear and logical choices in addition to using objectives, and scoring guides for preparation of essay questions can improve the reliability of these questions and in turn improve the success rates of students (18). Encouraging active learning can lead to a better performance of students in any type of questions included in the exam and it can improve success rates in general (19). The general success of students was $73.7 \%$ which represented 188 students out of 255 students.

\section{Conclusion:}

The success rate for both MCQ and EQs had no significant difference as compared to each other.

\section{Authors' contributions:}

The idea of the study and collection of data was done by Dr Affan Ezzat and Dr.Ghassan Thabet .The paper was written and organized by Dr.Hanan Luay and Dr.Zainab Muthana.

\section{References:}

1-Rust, C., O'Donovan, B. and Price, M.: A social constructivist assessment process model: how the research literature shows us this could be best practice. Assessment \& Evaluation in Higher Education. 2005, 30(3): 231-240.

2- Ebstein RM. Assessment in medical education: $N$ Engl J Med; 2007 , 356:387-96.

3- Scouller, K.M. and Prosser, M. : Students' experiences in studying for multiple choice question examinations. Studies in Higher Education. 1994, 19(3): 267-279.

4-Sally Jordan: Assessment for learning: pushing the boundaries of computer-based assessment. Practitioner Research in Higher Education. 2009, Vol 3 (1): page 11-19.

5- Sadler, D.R. :Formative assessment and the design of instructional systems. Instructional Science. 1989, 18: 119-144.

6- Hillard RI. The effects of examinations and the assessment process on the learning activities of undergraduate medical students [dissertation].
Department of education: University of Toronto; 1994.

7-Adewoye EO, Oyebola OD, Bamgboye EA. :A comparative study of students' performance in preclinical physiology assessed by short and long essays. Afr J Med Med Sci. 2000 ;29(2):155-9.

8-T.M. Nandan, G. Latha, Dhayakani Selvakumar and C.N. Veena: Comparison of Essay Type and Multiple Choice Questions for Theoretical Formative Assessment among Second Phase MBBS Students in Microbiology. International Journal of Current Microbiology and Applied Sciences .ISSN: 2319-7706, Volume 6 Number 5 ,2017.pp. 1529. 1537

9- Khan MZ, Aljarallah BM : Evaluation of Modified Essay Questions (MEQ) and Multiple Choice Questions (MCQ) as a tool for Assessing the Cognitive Skills of Undergraduate Medical Students .International Journal of Health Sciences.2011, Vol. 5, No. 1.P 39-43.

10- Mujeeb AM, Pardeshi ML, Ghongane BB: Comparative assessment of multiple choice questions versus short essay questions in pharmacology examinations.Indian $J$ Med Sci. $2010,64(3): 118-24$.

11 - Farley JK. : The multiple choice test: writing the questions. Nurse Educator 1989; 14:10-12, 39.

12- Haladyna TM, Downing, SM, Rodriguez MC. :A review of multiple-choice itemwriting guidelines. Applied Meas Educ. 2002,15:309-33.

12- Felliti GI, Smith EK :Modified essay questions: are they worth the effort? Med Educ. 1986 ; 20(2):126-32. 8.

14- Pepple DJ, Young LE, Carroll RG: A comparison of student performance in multiplechoice and long essay questions in the MBBS stage I physiology examination at the University of the West Indies (Mona Campus). Advances in physiology education. 2010, 1;34(2):86-9.

15- Fowell SL, Bligh JG.: Recent developments in assessing medical students. Postgraduate medical journal. 1998, 1;74(867):18-24.

16- McCoubrie P.: Improving the fairness of multiple-choice questions: a literature review. Medical teacher. 2004 ; 26(8):709-12.

17-Oyebola DD, Adewoye OE, Iyaniwura JO, Alada AR, Fasanmade AA, Raji Y. A :comparative study of students' performance in preclinical physiology assessed by multiple choice and short essay questions. African journal of medicine and medical sciences. $1999 ; 29(3-4): 201-5$.

18- Tuckman BW.: The essay test: a look at the advantages and disadvantages. Nassp Bulletin. 1993 , $1 ;$ 77(555):20-6.

19-Yoder JD, Hochevar CM.: Encouraging active learning can improve students' performance on examinations. Teaching of Psychology. 2005, 1; 32(2):91-5. 